\title{
Do You Enjoy Having More Than Others? Survey Evidence of Positional Goods
}

\author{
Fredrik Carlsson ${ }^{\mathrm{A}}$ \\ Olof Johansson-Stenman ${ }^{\mathrm{B}}$ \\ Peter Martinsson ${ }^{\mathrm{C}}$
}

Working Papers in Economics no 100, May 2003

\begin{abstract}
Although conventional economic theory proposes that only the absolute levels of income and consumption matter for people's utility, there is much evidence that relative concerns are often important. This paper uses a survey-experimental method to measure people's perceptions of the degree to which such concerns matter, i.e. the degree of positionality. Based on a representative sample in Sweden, income and cars are found to be highly positional, on average. This is in contrast to leisure and car safety, which may even be completely non-positional.
\end{abstract}

JEL Code: C90, D63

Keywords: Relative income, relative consumption, positional goods, surveyexperimental method, marginal degree of positionality

Financial support from the Swedish Agency for Innovation Systems and the Swedish Civil Aviation Administration is gratefully acknowledged.

A Department of Economics, Göteborg University, Box 640, 40530 Göteborg, Sweden; Ph +46 31 7734174; Fax +46 3177310 43; E-mail fredrik.carlsson@economics.gu.se.

${ }^{\mathrm{B}} \mathrm{Ph}+46317732538$; E-mail olof.johansson@economics.gu.se.

${ }^{\mathrm{C}} \mathrm{Ph}+4631$ 7735255; Fax +46 3177310 43; E-mail peter.martinsson@economics.gu.se. 


\section{Introduction}

One of the main characteristics of behavioural economics is that it takes the influence of social context seriously. In this paper we focus on the idea that people may prefer not only to have a high income and consumption level, but also to have more than others, and similarly that people get disutility if they are surrounded by others who have more than they do. Using survey-experimental methods on a representative random sample in Sweden, we measure people's perceptions of the degree to which relative income, and relative consumption of leisure, cars and car safety, matter.

The idea that relative income and consumption are important for people is far from new. Many prominent economists in the past, including Adam Smith, John Stuart Mill, Karl Marx, Alfred Marshall, Thorstein Veblen, Arthur Pigou, John Maynard Keynes and Tibor Scitovsky, have seriously discussed the observation that people seem to be concerned with their own income and consumption relative to that of others. Despite this fact and despite extensive recent, mainly theoretical, research on status and social comparisons (Weiss and Fershtman, 1998), such concerns are still treated as nonstandard and microeconomic textbooks rarely even raise the possibility that they might matter.

Whether relative income and consumption concerns exist and are substantial is important for our understanding of many economic phenomena, including aggregate consumption and savings patterns (Dusenberry, 1949; Basmann et al., 1988), ${ }^{1}$ wage formation (Agell and Lundborg, 1995, 2003), pricing of cosmetic products (Chao and Schor, 1998), labour supply (Neumark and Postlewait, 1998) and the demand for risky activities (Becker and Murphy, 2000). Furthermore, since relative concerns imply that

\footnotetext{
1 According to Frank (1985a), Dusenberry's relative-income based model explains aggregate consumption and savings patterns much better than the permanent income hypothesis (Friedman, 1957).
} 
an increased income or consumption level of each individual imposes negative externalities on the others, one can also argue in favour of policy interventions in response to an over-consumption of goods consumed primarily to demonstrate wealth or success - positional goods in the vocabulary of Hirsch (1976) and Frank (1985a, b). Remarkably, this was pointed out more than 150 years ago by John Stuart Mill, saying "I cannot but think that expenditure of this sort is a most desirable subject of taxation." (Mill, 1848, V vi: 869)

The idea that relative income matters is also consistent with the findings of modern happiness research. In this literature it is typically found that people's self-reported happiness, or subjective well-being, increases with income within a country at a given time, but that while average income increases over time, average happiness remains fairly constant, at least if a certain threshold income level has been reached. Similarly, when comparing different countries, the average happiness level appears to be almost independent of the average income level (e.g. Frey and Stutzer 2002a, b). The solution typically put forward to this paradox is the so-called Easterlin hypothesis: happiness increases with relative income, but is independent of absolute income levels (Easterlin 1974, 1995). Thus, this is the opposite to conventional economic theory where only absolute income matters.

One reason why economists have been reluctant to accept these conclusions is that they are based on statements of happiness and require interpersonal comparisons to be possible, whereas modern economics typically relies on revealed behaviour. For example, it has been suggested that for a person in a rich country "very happy" may reflect a higher degree of happiness on average than the same statement for a person in a poor country; see e.g. Brekke (1997) and Osmani (1993). Even though economists may 
have been unreasonably reluctant to use subjective well-being measures in general - see e.g. Blanchflower and Oswald (2002) and Frey and Stutzer (2002 a, b) for such arguments - it is nevertheless important to supplement these findings with other empirical methods to see if the conclusions are robust.

In order to quantify the degree to which relative concerns matter - the main task of this paper - it would clearly be an advantage if all non-essential variables could be fixed. The main advantage of using experimental or survey-based methods is that it affords this possibility. One example of a survey-experimental approach, and the one adopted here, is to let people make choices regarding hypothetical states of the world in order to reveal their perception of what is intrinsically important to them. In Solnick and Hemenway (1998), the respondents chose between one state where they are better off in absolute terms of a certain good, and another state where they are better off in relative terms compared to others. Similar designs were used by Johansson-Stenman et al. (2002) and Alpizar et al. (2003), although they also allowed the respondents to make repeated choices which enabled them to estimate the average degree to which relative income and consumption matter. These experiments have all been conducted with students, ${ }^{2}$ which is standard practice in behavioural and experimental economics, and would not be a source of concern in most instances (see e.g. Camerer and Fehr, 2003). However, sometimes it can be important to use "real people;" see e.g. Henrich et al. (2001, 2003). In our case it may be difficult for students with very limited experience of earning their own money, and consuming goods such as cars, to make these choices, which is why we have chosen to use a representative sample of Swedes.

\footnotetext{
${ }^{2}$ Solnick and Hemenway included some faculty and staff members in their experiment.
} 
Section 2 presents the design of the survey and experiment, and explains how the degree of positionality can be inferred from the responses. Section 3 quantifies the perceived mean degrees of positionality using three different methods: $i$ ) applying random utility theory by explicitly modelling the utility function, $i$ ) applying a random parameter method where the distribution of the coefficient reflecting positionality is instead modelled directly, and iii) by using a non-parametric approach. Section 4 summarizes and concludes the paper.

\section{The survey and experiment}

The main survey was sent out to 700 randomly selected individuals in Sweden in May 2002. Of these, 25 were returned due to "address unknown." Out of the remaining 675 questionnaires, $335(50 \%)$ were returned. The questionnaire consisted of two parts. The first part contained socio-economic questions and the second part contained the experiment. The experiment began with an introduction describing the basic idea and an example.

\footnotetext{
${ }^{3}$ Two weeks after the questionnaire was sent out, a reminder was sent out to those respondents who had not yet answered.
} 
In this part of the questionnaire we require you to choose which society you consider to be the best one for an imaginary person living two generations into the future. You can, for example, imagine a grandchild, great grandchild or another relative that you are choosing for. By 'best' we mean the society in which your future relative will be most content.

- The difference between the societies is the income level or the amount of consumption for a certain good of your future relative, and the average income and consumption of the society.

- The variety of goods and their prices are the same for both societies. For 100 SEK you can buy the same goods and the same amount in both societies. Prices are expressed in today's price level.

- It is important that you focus your answer on what is in the best interest of the imagined person, and nothing else. There is no "correct" response to these questions and we ask you to reflect on the choices carefully.

\section{Example}

In the example below your future relative earns 2000 SEK more in society A compared with society B. You can also see that your future relative earns $5000 \mathrm{k} / \mathrm{month}$ less than the average income in society A and 3000 $\mathrm{SEK} /$ month more than the average in society $\mathrm{B}$.

Society A

Society B
- Your relative's income is $20000 \mathrm{SEK} /$ month after tax.

- The average income in society is $25000 \mathrm{SEK} /$ month after tax.

- Your relative's income is $18000 \mathrm{SEK} / \mathrm{month}$ after tax.

- The average income in society is $15000 \mathrm{SEK} / \mathrm{month}$ after tax.

We require you to choose which society you consider to be the best one for your future relative; that is, the society in which your future relative will be most content. It is important that you focus your answer solely on this; that is: which society is the best for your future relative? You should not consider which society is best on the whole.

In the construction of the scenarios we followed Johansson-Stenman et al. (2002) and Alpizar et al. (2003) by instructing the respondents to consider the well-being of an imagined relative living two generations from now when making their choices. This framing was used in order to help the respondents to liberate themselves from their current circumstances, and it is possible that utility also depends on changes in income and consumption over time (i.e. positionality in the time-dimension); see e.g. Frank and Hutchens (1993). Moreover, it seems more natural to choose what is best for an imagined relative than a complete stranger.

The introduction and example were followed by four questions concerning income, leisure, the market value of cars, and car safety. Since making repeated choices on the same goods, such as in Alpizar et al. (2003), may induce anchoring problems, we only asked each respondent to make one choice per good investigated. Because an 
understanding of price levels is essential to the interpretation of the results, it was repeatedly stressed that the societies were identical in every other dimension, that the price levels were the same and that they were expressed in terms of the current price level in Sweden.

The first choice concerned the incomes of their relative and others. As in the example, the respondents made a choice between two societies, $\mathrm{A}$ and $\mathrm{B}$, that were described by the imagined relative's income and the average income in the two societies. There were three different versions, with different income levels, of which one is shown below (the levels of all versions for all goods are shown in Table 1).

\section{Question 1 Income for your future relative}

Choose between society A and B for your future relative.

Society A

Society B
- Your relative's income is $27000 \mathrm{SEK} /$ month after tax.

- The average income in society is $30000 \mathrm{SEK} / \mathrm{month}$ after tax.

- Your relative's income is $25250 \mathrm{SEK} / \mathrm{month}$ after tax.

- The average income in society is $22950 \mathrm{SEK} / \mathrm{month}$ after tax.

Everything else is the same in the two societies, including the price level. In both society A and B your relative works 40 hours per week, which is same as the average number of working hours. Choose the society that you consider to be the best for your future relative.

\section{$\square$ Society A}

$\square$ Society B

There are many ways to incorporate relative comparison into the utility function. Most studies have either used a ratio comparison utility function, $u(x, x / \bar{x})$, or an additive comparison utility function, $u(x, x-\bar{x})$, where $x$ is the individual's income and $\bar{x}$ is the average income in society. We follow Johansson-Stenman et al. (2002) and Brekke and Howarth (2002) and focus on the following ordinal ratio-comparison utility function $u=x^{1-\gamma}(x / \bar{x})^{\gamma}=x / \bar{x}^{\gamma} \cdot{ }^{4}$ Since the utility function is ordinal, any monotonic

\footnotetext{
${ }^{4}$ The only test we are aware of that empirically compares different functional forms is in JohanssonStenman et al. (2002). They compared this utility function with the additive comparison utility function
} 
transformation of it is an equally valid utility function (this will be utilized in Section 3). It is easy to see that $\gamma$ reflects the marginal degree of positionality, i.e. the fraction of the last dollar spent that comes from increased relative consumption. Thus, when $U=u(x, r) \equiv u(x, x / x)$ we have that $\gamma=\frac{\partial u}{\partial r} \frac{\partial r}{\partial x} /\left(\frac{\partial u}{\partial x}+\frac{\partial u}{\partial r} \frac{\partial r}{\partial x}\right)$

To quantify the strength of relative concern, let us consider the hypothetical choice between the two societies in Question 1. If an individual is indifferent, the utility is the same in $\mathrm{A}$ and $\mathrm{B}$, and hence $x_{A} / \bar{x}_{A}^{\gamma}=x_{B} / \bar{x}_{B}{ }^{\gamma}$. Solving for $\gamma$ and inserting the values gives us $\gamma=\ln \left[x_{B} / x_{A}\right] \ln \left[x_{B} / x_{A}\right]=0.25$. Thus, if an individual is indifferent, then $\gamma=0.25$, but if he or she prefers society A then $\gamma<0.25$ and vice versa. Given that the implicit marginal degree of positionality is varied among the respondents it is possible to estimate the mean value of $\gamma$ in the population. The marginal degree of positionality for the three different goods is calculated in a similar way.

In the second question we were interested in whether relative concerns also matter for leisure, which is typically seen as a non-positional good; see e.g. Frank (1985a, 1999). From a policy perspective, this is a particularly important issue, since large positionality differences between income and leisure may partly or totally offset the distortions that are typically associated with income taxes due to the fact that leisure is considered impossible to tax. Instead of presenting the leisure time per week we presented the number of working hours. Respondents are presumably more familiar with this, and we can infer the amount of leisure time from that. One version of the labour/leisure question is shown below.

$u=x-\delta \bar{x}$. They found that the ratio comparison function performed better in terms of explaining respondent behavior, but they also concluded that more research is needed. Nevertheless, in our case all results are very similar for the two utility functions. 


\section{Question 2 Working hours and leisure for your future relative}

Choose between society A and B for your future relative. The societies are the same except for the information given below.

Society A

Society B
- Your relative's working hours are 40 hours per week.

- Average working hours are 36 hours per week.

- Your relative's working hours are 42.5 hours per week.

- Average working hours are 46 hours per week.

Everything else is the same in the two societies, including the price level. In both society A and B your relative's monthly income is $20000 \mathrm{SEK}$, which is the same as the average income. Choose the society that you consider to be the best for your future relative.

The last two choices concerned the value of the relative's car and the safety of the car, respectively. How much to spend on these goods is clearly up to the consumer in a free society. ${ }^{5}$ However, for our purposes we do not want the respondents to interpret the prescribed consumption as reflections of their future relative's free choice. ${ }^{6}$ Therefore we explained that the company at which the relative works provides the car as a fringe benefit, which is a common practice in Sweden. One version of the value-of-car question is shown below.

\footnotetext{
${ }^{5}$ The same could be claimed for the work-leisure tradeoff, but it is more common with restrictions in that choice, at least in Sweden.

${ }^{6}$ For example, we do not want them to reason in the following way: "A relatively small amount spent on cars probably reflects that my relative is uninterested in the status value of cars, and prefers to spend more money on for example clothes instead." Furthermore, a lower or higher market value for the car could be interpreted as more or less consumption of other goods.
} 


\section{Question $3 \quad$ Market value of the car for your future relative}

Choose between society A and B for your future relative. The societies are the same except for the information given below. This means the consumption of all other goods is the same in both societies even if the market value of cars is higher in one society. The company at which your relative works provides a company car.

Society A

Society B
- Your relative's company car is a few years old with a market value of 90000 SEK.

- The average market value of cars in the society is 100000 SEK

- Your relative's company car is a few years old with a market value of 84200 SEK

- The average market value of cars in the society is $76500 \mathrm{SEK}$

Everything else is the same in the two societies, including the price level and your relative's income. Choose the society that you consider the best for your future relative.

$\square$ Society A

$\square$ Society B

In the question on car safety, the levels were expressed as fatal accident risks and they

were all related to today's mean risk level of the car stock, which according to the

Swedish insurance company, Folksam, corresponds to the safety level of a Ford Escort

from 1995. One version of the question is presented below.

\section{Question $4 \quad$ Car safety for your future relative}

Choose between society A and B for your future relative. The societies are the same except for the information given below. The company at which your relative works provides a company car. Today a 1995 Ford Escort has a mean risk for fatal accidents in Sweden (based on an analysis by Folksam); we therefore compare the future cars with this car.

Society A

- Your relative has a company car with a mean accident risk that is $16 \%$ lower than for a 1995 Ford Escort

- The average car in the society has a mean accident risk that is $25 \%$ lower than for a 1995 Ford Escort.

Society B

- Your relative has a company car with a mean accident risk that is $10 \%$ lower than for a 1995 Ford Escort.

- The average car in the society has a mean accident risk that is $2 \%$ lower than for a 1995 Ford Escort.

Everything else is the same in the two societies, including the price level. Choose the society that you consider to be the best for your future relative. 
Again, the definition of the marginal degree of positionality is equivalent to the income case: Denoting safety with $s$ we can write the utility function, holding everything else constant, as: $u=s^{1-\gamma}(s / \bar{s})^{\gamma}=s / \bar{s}^{\gamma}$. Denoting the baseline safety $s_{0}$ and the percentage risk reduction compared to the baseline risk $\Delta r$, we have $s=s_{0} /(1-\Delta r)$ and $\bar{s}=s_{0} /(1-\Delta \bar{r})$. Substituting and solving for $\gamma$ when utility is the same in society A and B then gives: $\gamma=\ln \left[\left(1-\Delta r_{B}\right) /\left(1-\Delta r_{A}\right)\right] / \ln \left[\left(1-\Delta r_{B}\right) /\left(1-\Delta r_{A}\right)\right]$, which is equal to 0.25 in the case above.

For each good there were three different versions. These correspond to varying degrees of positionality if the respondent is indifferent, where the chosen degrees of positionality were $0.25,0.5$ and 0.75 . The respondents were randomly assigned to one of the three versions. For simplicity, each survey version had the same implicit degree of positionality across goods. In all three versions, Society A was kept the same so that the levels were only changed in Society B. Table 1 below presents the different versions of the experiment, as well as the corresponding shares of the respondents choosing society B, i.e. the society chosen if the relative concerns outweigh the absolute differnces between the societies.

$<<$ Table 1

There are clear differences, in the expected direction, between the responses to the various goods. For example, in survey version 1, where indifference to the choice between $\mathrm{A}$ and $\mathrm{B}$ reflects a marginal degree of positionality of $0.25,60 \%$ of the respondents preferred society $\mathrm{A}$ in the case of leisure, i.e. they preferred the society where the absolute amount of leisure is highest, but only $25 \%$ of the respondents chose 
society $\mathrm{A}$ in the case of income. Hence, already from this table it seems clear that income and the value of cars are more positional than leisure and car safety, on average. $^{7}$

\section{Estimating the Mean Marginal degree of Positionality}

We do not directly observe each respondent's degree of positionality, only whether it is smaller or larger than a certain value. Even so, we do observe the proportions of choices for each version of the survey, which we can use to estimate the mean marginal degree of positionality. We will use three different methods: $i$ ) applying the random utility theory by explicitly modelling the utility function, $i$ ) direct modelling of the coefficient reflecting positionality, and iii) by using a non-parametric method.

First we focus on the random utility model (RUM), which explicitly models the utility function by taking individuals' errors, as well as preference heterogeneity, into account through a random component of the utility function (McFadden, 1974). This is particularly realistic in our case, since we cannot rule out the possibility that some respondents had difficulties in understanding the experiment, and that some may have been tired or unable to concentrate. Since the utility function is ordinal, we can use a simple monotonic transformation and express it as follows in the case of income (the other goods can be treated analogously):

$$
v=\alpha+\beta_{1} \ln x-\beta_{2} \ln \bar{x}+\varepsilon,
$$

\footnotetext{
${ }^{7}$ In order to test for scale effects we let another sample of respondents answer a high-scale version of the experiment where all levels were approximately doubled. However, these responses were of poor quality, presumably due to the cognitive difficulties of dealing with income and consumption levels far beyond most respondents' experience. We have therefore chosen not to report these results, although they are available from the authors upon request.
} 
where $\varepsilon$ is an error term, reflecting choice errors and preference heterogeneity, and where the marginal degree of positionality is given by: $\gamma=\beta_{2} / \beta_{1}$. The probability that an individual chooses society B is the same as the probability that the perceived utility of choosing society $\mathrm{B}$ is higher than the one of choosing $\mathrm{A}$. We can then express the probability that an individual chooses society B as:

$$
\begin{gathered}
\operatorname{Pr}[B]=\operatorname{Pr}\left[\alpha+\beta_{1} \ln x_{A}-\beta_{2} \ln \bar{x}_{A}+\varepsilon_{A}<\alpha+\beta_{1} \ln x_{B}-\beta_{2} \ln \bar{x}_{B}+\varepsilon_{B}\right] \\
=\operatorname{Pr}\left[\beta_{1} \ln \left(\frac{x_{A}}{x_{B}}\right)+\beta_{2} \ln \left(\frac{\bar{x}_{B}}{\bar{x}_{A}}\right)<\eta\right],
\end{gathered}
$$

where $\eta=\varepsilon_{B}-\varepsilon_{A}$. If we assume that the error terms are standard normally distributed, the parameters in the utility function in (1) can be estimated with a binary probit model, and the estimated mean degree of marginal positionality is given by the ratio of the estimated parameters $\beta_{2}$ and $\beta_{1}$.

An alternative is to investigate their choice directly and make an assumption about the distribution of the degree of positionality; we call this approach a random parameter model (RPM). Assuming a symmetric positionality distribution we can write:

$$
\gamma=\alpha+\varepsilon,
$$

where $E[\gamma]=\alpha$ and $\operatorname{var}[\gamma]=\operatorname{var}[\varepsilon]=\sigma^{2}$. The probability that an individual chooses society B depends on the survey version he/she answered, i.e. on the implicit degree of positionality when he/she is indifferent to the choice between $\mathrm{A}$ and $\mathrm{B}(0.25,0.5$ or 0.75). Let us denote that level in survey version $j$ by $\mathrm{g}_{j}$. We then have:

$$
\operatorname{Pr}[B]=\operatorname{Pr}\left[\alpha+\varepsilon>g_{j}\right\rfloor=\operatorname{Pr}\left[\alpha-g_{j}>\varepsilon\right] .
$$


If we assume that the error terms are standard normal distributed, $\alpha$ can be estimated with a binary probit model with an intercept and $g$. The mean degree of positionality is then given by the ratio of the intercept and the coefficient for $g .{ }^{8}$

Finally we consider a non-parametric approach, where we use the so-called Spearman-Karber estimator. Essentially, this means that we make linear interpolations between the observed shares of choices of societies at the different implicit degrees of positionality. The disadvantage of this method is that it does not reflect preference uncertainty and cognitive limitations, i.e. it implicitly assumes that all responses are deterministic. On the other hand, it is well known that the other methods are sensitive to the distributional assumptions being made, and a non-parametric approach is naturally more robust in this sense. The mean marginal degree of positionality, using this method, is then calculated as

$$
E[\gamma]=\sum_{j=1}^{4} \frac{\left(P_{j}-P_{j+1}\right)\left(g_{j}+g_{j+1}\right)}{2},
$$

where $P_{j}$ is the share of respondents who choose society B when the implicit degree of positionality is equal to $g_{j}$. In order to estimate the mean, we have to make assumptions about the lower and upper bounds of the distribution. We have tested different assumptions, with relatively minor differences between the results and we report the results for the case where $\gamma$ is distributed between -0.25 and 1.25 .

Table 2 reports the mean degrees of positionality, and the corresponding $95 \%$ confidence intervals for income and the different goods based on the three different

\footnotetext{
${ }^{8}$ The reason for this is that the estimated coefficient for the implicit degree of positionality is equal to the inverse of the variance parameter cnf. Cameron (1988).
} 
methods described above. ${ }^{9}$ As can be seen, the mean degrees for leisure and safety are always considerably lower than the mean degrees for income and market value for cars. Indeed, for both the RUM and the RPM estimations, the marginal degree of positionality for leisure and car safety is not statistically larger than zero at the $10 \%$ level, whereas the values for income and the value of a car are significantly different from zero at the $1 \%$ level. Furthermore, the marginal degree of positionality for the value of a car is not significantly smaller than one at the $10 \%$ level, based on the two parametric methods. Hence, it cannot be ruled out, based on these findings, that the value of cars is purely positional. ${ }^{10}$ In the non-parametric approach the marginal degree of positionality is significantly different from both zero and one at the $1 \%$ level for all goods.

$<<$ Table 2.

The results can be compared with Alpizar et al. (2003), who found that on average about half of the utility obtained from an additional dollar comes from relative concerns, and that this share was higher for private cars and housing, and substantially lower for leisure and insurances. These results are more or less in line with the ones presented here. It is worth noting that the degree of positionality obtained for leisure is somewhat lower than the one obtained by Alpizar et al. for the number of weeks of vacation, based

\footnotetext{
9 For the non-parametric model the variance of the mean estimate is given by $V[E(\gamma)]=\sum_{j=2}^{4} \frac{P_{j}\left(1-P_{j}\right)\left(g_{j+1}-g_{j-1}\right)^{2}}{4\left(N_{j}-1\right)}$, where $N_{j}$ is the number of respondents. For the RUM and the RPM the variances are estimated using the Delta method (Greene, 2000).

${ }^{10}$ Strictly speaking, it cannot be ruled out for leisure either, based on the RUM estimations. This is due to the very large standard deviation, which is probably related to the rather high share of respondents that choose society A already at a low implicit degree of positionality, combined with the distributional assumptions.
} 
on comparable non-parametric methods. This may imply that the number of weeks of vacation is more positional than leisure in general. Furthermore, using methods that allow for preference uncertainty and choice errors, we cannot reject the hypotheses that leisure and car safety are completely non-positional, i.e. that only the absolute levels matter for these goods. Moreover, the results follow intuition, and previous predictions, in the sense that the goods that are more visible are also the ones that are more positional.

\section{Conclusions}

In this paper we have measured people's perceptions of the importance of relative income and consumption. As far as we know, this is the first time that $i$ ) surveyexperimental methods on positionality have been based on a random sample of the population, $i$ i) the measurement of positionality is linked to random utility theory, and iii) the degree of positionality for leisure and safety has been measured explicitly. ${ }^{11}$ Our analysis shows that relative income and relative consumption of at least some goods matter. It also shows that some goods are more positional than others, where the difference is in the expected direction where the more visible goods are also more positional. Moreover, from our results we cannot rule out that the value of a private car is completely positional, whereas leisure and the safety of cars may be completely nonpositional.

The fact that relative income and relative consumption matter to an individual implies that the income and consumption of others affect the individual's utility negatively. However, this does not imply that an individual, when offered the

\footnotetext{
${ }^{11}$ Alpizar et al. (2003) focused on weeks of vacation, which do need not reflect overall leisure accurately.
} 
possibility, would try to decrease the income or consumption of others. Indeed, there is ample experimental evidence for the opposite behaviour; see e.g. Fehr and Schmidt (1999), Bolton and Ockenfels (2000), Charness and Grosskopf (2001) and Charness and Rabin (2002). This may seem to be a contradiction. However, the fact that people sometimes voluntarily give their money to others, as typically observed in for example dictator games, does not imply that people get utility from seeing that others have more. It shows that under certain contexts person A prefers to give money to person $\mathrm{B}$, but it certainly does not show that A would be better off if B were to find the same amount of money on the street. Why people voluntarily give money to others in certain situations is beyond the scope of this paper, but there is much evidence that it is strongly related to people's perceptions of fairness and reciprocity (Fehr and Gächter, 2000; Fehr and Fischbacher, 2002; Charness and Rabin, 2002).

Finally, we are fully aware of the fact that, like other known methods, the method used here to measure the importance of relative concerns has drawbacks. ${ }^{12}$ Nevertheless, since the degree of the disagreement within the scientific community is enormous on these issues, ranging from one extreme where only absolute income and consumption matter, to the other extreme where only relative income and consumption matter, we believe that the marginal benefit of providing new empirical information in this field is large. We therefore encourage the development and use of alternative methods to shed further light on these issues.

\footnotetext{
${ }^{12}$ For example, as discussed by Alpizar et al. (2002), there are reasons why one may suspect that some people would have systematic perception biases.
} 


\section{References}

Agell, J. and P. Lundborg (1995), Theories of Pay and Unemployment: Survey Evidence from Swedish Manufacturing Firms, Scandinavian Journal of Economics, 97(2), 295-307.

Agell, J. and P. Lundborg (2003), Survey Evidence on Wage Rigidity and Unemployment: Sweden in the 1990s, Scandinavian Journal of Economics, 105(1), $15-29$.

Alpizar, F., F. Carlsson and O. Johansson-Stenman (2003), How Much Do We Care About Absolute versus Relative Income and Consumption?, Journal of Economic Behavior and Organization, forthcoming.

Basmann, R. L., D. J. Molina and D. J. Slottje (1988), A Note on Measuring Veblen's Theory of Conspicuous Consumption, Review of Economics and Statistics, 70, 53135 .

Becker, G.S. and K.M. Murphy (2000), Social Economics. Market Behavior in a Social Environment. The Belknap Press of Harvard University Press: Cambridge, Massachusetts.

Blanchflower, D. and A.J. Oswald (2002) 'Well-Being Over Time in Britain and the USA', Journal of Public Economics, forthcoming.

Bolton, G. E., and A. Ockenfels (2000), ERC - A Theory of Equity, Reciprocity, and Competition, American Economic Review 90, 166-93.

Brekke, K.-A. (1997). Economic Growth and the Environment. Cheltenham: Edward Elgar.

Brekke, K.-A. and R.B. Howarth (2002), Status, Growth and the Environment, Cheltenham, Edward Elgar.

Camerer, C.F. and E. Fehr (2003), Measuring Social Norms and Preferences Using Experimental Games: A Guide for Social Scientists. In Henrich et al. (2003).

Cameron, T. (1988), A New Paradigm for Valuing Non-Market Goods Using Referendum Data: Maximum Likelihood Estimation by Censored Logistic Regression, Journal of Environmental Economics and Management 15, 355-379.

Chao, A. and J. B. Schor (1998), Empirical Tests of Status Consumption: Evidence from Women's Cosmetics, Journal of Economic Psychology 19, 107-31.

Charness, G. and B. Grosskopf (2001), Relative Payoffs and Happiness: An 
Experimental Study, Journal of Economic Behavior and Organization 45, 301-28.

Charness, G., and M. Rabin (2002), Understanding Social Preferences with Simple Tests, Quarterly Journal of Economics 117, 817-69.

Duesenberry, J.S. (1949), Income, Saving, and the Theory of Consumer Behaviour, Cambridge: Harvard University Press.

Easterlin, R.A. (1974), Does Economic Growth Enhance the Human Lot? Some Empirical Evidence, in P.A. David and M. Reder (eds.) Nations and Households in Economic Growth: Essays in Honour of Moses Abramovitz. Palo Alto: Stanford University Press.

Easterlin, R.A. (1995), Will Raising the Incomes of All Increase the Happiness of All?, Journal of Economic Behavior and Organization 27, 35-47.

Fehr, E. and U. Fischbacher (2002), 'Why Social Preferences Matter - The Impact of Nonselfish Motives on Competition, Cooperation, and Incentives' Economic Journal, 112, C1-C33.

Fehr, E. and S. Gächter (2000), Cooperation and Punishment in Public Goods Experiments, American Economic Review 90, 980-94.

Fehr, E. and K.M. Schmidt (1999), A theory of fairness, competition and cooperation, Quarterly Journal of Economics 114, 817-868.

Frank, R.H (1985a), Choosing the Right Pond: Human Behavior and the Quest for Status, New York: Oxford University Press.

Frank, R.H. (1985b), The Demand for Unobservable and Other Nonpositional Goods". American Economic Review 75, 101-16.

Frank, R. H. (1999) Luxury Fever: Money and Happiness in an Era of Excess, The Free Press.

Frank, R.H. and R.M. Hutchens (1993), Wages, Seniority, and the Demand for Rising Consumption Profiles, Journal of Economic Behavior and Organization 21, 251-76.

Frey, B. S. and A. Stutzer (2002a), Happiness and Economics: How the Economy and Institutions Affect Human Well-Being. Princeton University Press.

Frey, B. S. and A. Stutzer (2002b), What Can Economists Learn from Happiness Research?" Journal of Economic Literature 40, 402-35.

Friedman, M (1957), A Theory of the Consumption Function, Princeton University Press. 
Greene, W.H. (2000), Econometric Analysis, Prentice-Hall: New Jersey.

Henrich, J., R. Boyd, S. Bowles, C. Camerer, E. Fehr, H. Gintis, R. McElreath (2001), In Search of Homo Economicus: Behavioral Experiments in 15 Small-Scale Societies, American Economic Review, Papers and Proceedings 91, 73-78.

Henrich, J., R. Boyd, S. Bowles, H. Gintis, E. Fehr, R. McElreath, (2003), Foundations of Human Sociality - Experimental and Ethnograhic Evidence from 15 Small-Scale Societies, Oxford University Press.

Hirsch, F. (1976), Social Limits to Growth, Cambridge. Harvard University Press.

Johansson-Stenman, O., F. Carlsson and D. Daruvala (2002), Measuring Future Grandparents' Preferences for Equality and Relative Standing, Economic Journal $112,362-383$.

McFadden, D. (1974). Conditional Logit Analysis of Qualitative Choice Behavior, in P. Zarembka (ed.), Frontiers in Econometrics, New York: Academic Press.

Mill, J.S. (1848), Principles of political Economy.

Neumark, D. and A. Postlewait (1998), Relative Income Concerns and the Rise in Married Women's Employment Journal of Public Economics 70, 157-83.

Osmani, A.J. (1993), Comment on B.M.S. van Praag: The relativity of the welfare concept. In (M. Nussbaum and A. Sen, eds) The Quality of Life. Oxford: Oxford University Press.

Solnick, S. and D. Hemenway (1998), Is More Always Better?: A Survey on Positional Concerns, Journal of Economic Behavior and Organization 37, 373-383.

Weiss, Y. and C. Fershtman (1998), Social Status and Economic Performance: A Survey, European Economic Review 42, 801-820 
Table 1. Societies and descriptive results from the experiment.

\begin{tabular}{|c|c|c|c|c|}
\hline & $\begin{array}{c}\text { Relative's } \\
\text { income or } \\
\text { consumption }\end{array}$ & $\begin{array}{c}\text { Average } \\
\text { income or } \\
\text { consumption }\end{array}$ & $\begin{array}{c}\text { Positionality }(\gamma) \\
\text { if indifferent }\end{array}$ & $\begin{array}{c}\text { Share of } \\
\text { respondents } \\
\text { choosing society B }\end{array}$ \\
\hline \multicolumn{5}{|c|}{ Income experiment; SEK/month } \\
\hline Society A (all versions) & 27000 & 30000 & & \\
\hline Society B, version 1 & 25250 & 22950 & 0.25 & $75 \%$ \\
\hline Society B, version 2 & 22000 & 20000 & 0.5 & $53 \%$ \\
\hline Society B, version 3 & 14800 & 13450 & 0.75 & $47 \%$ \\
\hline \multicolumn{5}{|c|}{ Leisure experiment; working hours/week } \\
\hline Society A (all versions) & 40 & 36 & & \\
\hline Society B, version 1 & 42.5 & 46 & 0.25 & $40 \%$ \\
\hline Society B, version 2 & 47 & 51 & 0.5 & $19 \%$ \\
\hline Society B, version 3 & 61 & 64 & 0.75 & $10 \%$ \\
\hline \multicolumn{5}{|c|}{ Car consumption experiment; market value in SEK } \\
\hline Society A (all versions) & 90000 & 100000 & & \\
\hline Society B, version 1 & 84200 & 76500 & 0.25 & $61 \%$ \\
\hline Society B, version 2 & 73600 & 69600 & 0.5 & $56 \%$ \\
\hline Society B, version 3 & 49300 & 44800 & 0.75 & $50 \%$ \\
\hline \multicolumn{5}{|c|}{ Car safety experiment; risk of fatal accident relative to the average risk of cars 2002} \\
\hline Society A (all versions) & $17 \%$ lower & $25 \%$ lower & & \\
\hline Society B, version 1 & $10 \%$ lower & $2 \%$ lower & 0.25 & $45 \%$ \\
\hline Society B, version 2 & $7 \%$ higher & $17 \%$ higher & 0.55 & $22 \%$ \\
\hline Society B, version 3 & $52 \%$ higher & $67 \%$ higher & 0.75 & $10 \%$ \\
\hline
\end{tabular}

Table 2. Estimates of the mean degrees of positionality $(\gamma)$ for income and different goods, using three different empirical methods; $95 \%$ confidence interval in parenthesis.

\begin{tabular}{lccc}
\hline & Random utility model & Random parameter model & Non-parametric method \\
\hline Income & 0.71 & 0.66 & 0.59 \\
Leisure & $(0.62-0.80)$ & $(0.54-0.77)$ & $(0.54-0.65)$ \\
Car & -2.40 & 0.12 & 0.24 \\
& $(-12.33-7.53)$ & $(-0.20-0.26)$ & $(0.19-0.28)$ \\
Safety & 0.74 & 0.75 & 0.56 \\
& $(0.60-0.89)$ & $(0.38-1.13)$ & $(0.50-0.61)$ \\
& -0.18 & 0.20 & 0.27 \\
& $(-1.04-0.67)$ & $(0.08-0.31)$ & $(0.23-0.32)$ \\
\hline
\end{tabular}

